\title{
STRATEGIES USED BY SOUTH AFRICAN NON-ELITE ATHLETES TO COPE WITH THE ENVIRONMENTAL STRESSORS ASSOCIATED WITH ENDURANCE EVENTS
}

\author{
John W. O'NEIL \& Barend J.M. STEYN \\ Department of Biokinetics, Sport and Leisure Sciences, University of Pretoria, Pretoria, \\ Republic of South Africa
}

\begin{abstract}
The aim of this study was to determine the coping strategies that non-elite athletes use to overcome environmental factors during endurance events. A sample of 53 nonelite endurance athletes completed a questionnaire and interviews were conducted. The research focused on exploring individual experiences as well as identifying themes and patterns of behaviour during endurance events. The results indicated that endurance athletes used basically three coping strategies (responses) that were identified in the literature. The most frequently used strategy was to remove the source of the stress followed by strategies that change the athlete's perception of the stressor and lastly strategies that deal with the symptoms of the stressor. Most of the endurance athletes perceive problems and challenges to be a positive experience. The majority of endurance athletes have a positive perception of their own abilities and regularly place themselves in situations of danger or extreme stress to test this ability. This ability must, however, constantly be tested by participation in endurance sport or other stressful situations. Previous successful participation in endurance events or other stressful situations leads to an increase in positive self-perception of own abilities, as well as an increase in performance in endurance events.
\end{abstract}

Key words: Endurance events; Stress; Environmental stressors; Coping strategies.

\section{INTRODUCTION}

Since the first marathon in ancient Greece, athletes have shown a desire to prove their physical and mental abilities by pushing themselves to go faster, further and higher. Fortunately, people are created and programmed with the capacity to adapt to and overcome obstacles and challenges. The core question that is relevant for this study is "how do athletes persevere in the face of adversity?" (Eliot, 2005: 3). One activity that exemplifies this need is the growing participation in endurance sport in South Africa. Endurance events can be defined as the ability to withstand longer strain, because the distance, time and the level of anaerobic fitness/intensity requirements for successful completion are considerably higher than when compared to other sport events (Brook, 1987; Jarver, 1989; Seiler, 1996; Mann \& Schaad, 2001; Kellmann, 2002). The physical and mental challenges of endurance sport are extreme and demand a great deal of preparation, sometimes months and years of preparation for one event. Once the event starts, the athlete has to overcome extreme challenges to the body as well as the mind in order just to finish. Endurance sport provides sports enthusiasts with the opportunity to test their physical and mental abilities to determine their capability to withstand extreme environmental conditions associated with endurance events. 
A factor that increases endurance athletes' levels of stress is the environment within which they are participating. Extreme environmental conditions in endurance sport can be defined as those environmental conditions or characteristics of the specific sport that place extreme physical and mental pressures on the athlete (Dettweiler, 1991; Anthony, 1996; Mann \& Schaad, 2001). These pressures or stressors, when not correctly managed, can have psychological, cognitive and physical effects ranging from perceptual distortions to lower performance and extreme physical injuries or even death. The endurance sport that are included in this study are marathon running, cross country running, road cycling, ultra distance road running, mountain biking, adventure racing, mountaineering, endurance swimming, endurance horse riding, canoeing and kayaking. Environmental stressors in endurance sport include heat, cold, altitude, lack of nutrition, lack of hydration, terrain, distance, sleep deprivation, rain, wind and equipment (Dettweiler, 1991; Bloomfield et al., 1992; Anthony, 1996; Armstrong, 2000; Mann \& Schaad, 2001).

Reactions to extreme environments are strongly mediated by psychological factors. If extreme environments are not seen as noxious or alarming, they will produce less or even opposite physical responses. If humans are able to prevent, control, avoid or respond to stressors, they will usually not become ill or injured and will perceive the stressor(s) and their own ability to cope more positively (Van Breda, 2001). Coping strategies may influence or change the amount of strain that the individual experiences when exposed to a stressful environment. Mediators can lower or enhance the level of physiological strain experienced. Physiological and behavioural changes occur sometimes even before a stressor is experienced in anticipation of and in preparation for challenges, threats or danger. Individuals and groups that have to survive and perform under extreme conditions need to utilize certain coping strategies to cope effectively with the extreme environment and to motivate themselves to survive and perform.

Coping strategies can further be described as skills, techniques, attitudes and behaviour learned in an ongoing process through life. Wann emphasises the importance of Anshel's COPE model that provides a very effective cognitive and behaviour strategy where the participant "focuses on controlling emotions, organizing input, planning the next response and executing the response" (COPE) (Wann, 1997: 212). This COPE model of Anshel (1990) is applicable to acute and temporary stressors focuses. They can be either active (conscious/rational) or avoidant behavioural or psychological responses. Active coping strategies are conscious, rational learned behavioural, emotional, cognitive or social responses used to minimize the effect of or the sources of stress and anxiety (Aldwin, 1993; Reber, 1995; Taylor, 1998; Van Breda, 2001; Cox, 2002; Levin, 2003; Weinberg \& Gould, 2003). A number of authors (Taylor, 1998; Van Breda, 2001; O’Neil, 2002) have identified three main types of coping responses. Firstly, responses that change the source of the stress or the situation from which the strainful experience emanates. Secondly, responses that change the individual's perception of the stressor or that control the meaning of the strainful experience and thirdly, responses that control the symptoms of stress itself after it has emerged. These coping responses or strategies were used to categorise coping responses of the athletes participating in this study. For a person to use coping strategies, the individual must perceive (consciously or unconsciously) that a threatening, dangerous or hazardous situation or condition is present. When a threatening, dangerous or hazardous situation or condition is perceived, the individual must be motivated to overcome the threatening situation or condition before active coping strategies can be used. Selye (1974) refers to this coping ability as the 
general adaptation syndrome (GAS) which is initiated by an alarm reaction followed by a mobilized resistance and ends with exhaustion if the stress is not eliminated or changed.

\section{PROBLEM STATEMENT AND AIM OF THIS STUDY}

Very little research has focused on the psychological dimension of endurance sport is limited (Campen \& Roberts, 2001). Little is known about the strategies that athletes employ to cope with the stressors of endurance events (Campen \& Roberts, 2001; Weinberg \& Gould, 2003). The aim of this study was to determine the coping strategies athletes use to overcome the environmental stressors of endurance sport. The salutogenic model of health was used in this study to examine the coping strategies of athletes. In contrast to the pathogenesis approach which looks at the reasons why people are unable to cope, the salutogenic model looks at the reasons why people are able to cope with the stressors of different situations (Antonovsky, 1991; Van Breda, 2001). By using this approach, the researcher attempted to establish how athletes are able to overcome the challenges inherent in endurance sport.

\section{METHODOLOGY}

The basic approach of this study was not to verify or test known concepts, but rather to explore relatively unknown areas such as unknown and peculiar perceptions of environmental stressors and the unique ability of participants to cope with these environmental stressors. The focus was to explore individual experiences in endurance events as well as to identify themes and patterns of cognitions, emotions and behaviour of these athletes. By identifying these patterns, the researcher could identify concepts and themes of cognitions, emotions and behaviour that are associated with endurance events. To achieve this aim a qualitative research approach was followed. This study was conducted in two phases with experienced non-elite endurance athletes. The initial sample consisted of 85 athletes from the different endurance disciplines that were already stipulated. Experienced non-elite endurance athletes in this study are people who have participated in at least four endurance events, two in the past year, without being professional athletes (non-paid). However, several of the respondents were found to be unsuitable due to the fact that they had not participated in endurance sport or were not experienced enough. The final sample for this study consisted of 53 experienced non-elite endurance athletes. These athletes were selected on the grounds of their availability and willingness to participate in the study. Participation in this study was voluntary. The information received was kept anonymous and confidential. A questionnaire was specifically developed for this study based on the research problem. The questionnaire used in this study required the participants to report on the effect of environmental stressors, additional stressors, motivation to participate, motivational strategies and coping strategies during endurance events. The questionnaire was compiled from the intensive literature research and it was refined and calibrated through a thorough pilot study before the actual research was carried out. The pilot group consisted of a group of 15 endurance athletes that fulfilled all the requirements of the inclusion criteria of this study. Possible problematic and ambiguous questions were identified, altered, removed and if necessary replaced. This method was also used to gather descriptive, explanatory and explorative data (Babbi, 1995). The questionnaire and follow-up clarification interviews were conducted in a confidential environment where the participants' identity was protected. 
In the first phase of data gathering, the participants completed a questionnaire. Apart from biographical information (age, ethnic group, gender), all the items of the questionnaire consisted of open-ended questions. In the second phase (informal unstructured interviews), the researcher discussed the responses for the questionnaire with the majority of available participants to clarify their responses as well as the specific meaning of each response. Each interview differed according to the responses given by each participant.

The qualitative data analysis consisted of five distinctive phases: 1) organising the data; 2) generating categories; 3) identifying patterns and themes; 4) testing the emerging themes against the data; 5) searching for alternative explanations of the data (Marshall \& Rossman, 1995). In each phase of data analysis, data reduction is crucial as the mass of collected data is organised and ordered into manageable chunks or themes after which the researcher interprets the themes in order to give meaning to and insight into the words of the participants. By grouping similar responses together, categories of meaning or themes emerge. Grouping and ordering the responses of the participants under certain specific themes (related to the theory and literature), the researcher was able to identify patterns of behaviour, individual differences between athletes and similarities of meaning and experiences. This changed as the analysis progressed since the nature of qualitative research is fluid, adaptable and changeable to suit the nature of the data. This approach allowed the researcher to really get in the heads of the participants and facilitated the participants to elaborate fully on their own unique experiences of endurance events. A non constricted interview environment was created to allow the richness of personal experiences to be expressed optimally (Babbi, 1995; Hesse-Biber \& Leavy, 2004; Marschan-Piekkari \& Welch, 2004).

\section{RESULTS AND DISCUSSION}

The majority of participants $(62 \%)$ preferred to utilise the strategy that changes the source of the stress, whereas $36 \%$ of the participants utilised the strategy that changes the individual's perception of the stressor. This differs from previous research that found that a strategy that changes the perception of stress is more commonly used than any of the other two strategies (Van Breda, 2001). Only a small portion of the participants (2\%) utilised a strategy that focused on the symptoms of the stress. This finding is supported by research conducted by Gould et al. (1993a), Stevenson and Biddle (1998), Dale (2000) and Lazarus (2000). Additional research by Gould et al. (1993b), Anshel and Kaissidis (1997), and Weinberg and Gould (2003) showed that combinations of strategies seem to be most effective and that those athletes who were prepared for unexpected situations (strategy that changes the source of the stress) were more successful than athletes who did not prepare for such situations.

Figure 1 shows the distribution of coping strategies of each environmental stressor. The strategy that changes the source of stress is mostly visible in the environmental stressor of dehydration and equipment. The following responses are examples where the athletes take action to remove the factor that causes the stress, for example dehydration:

\footnotetext{
"Loads of water, try to take in salt beforehand. Rest in the shade".

"Get in shade, take of heavy equipment, try to relax and drink a lot of water".

"Whenever your body needs water your mouth feels dry so immediately I drink water and wipe my face and carry on".
} 
"Sit down and get water and rest till strength is back".

In terms of the equipment the following responses are typical of the well prepared ultra distance athlete:

"I look after my equipment".

"Just keep on going as far as possible if it is broken. Will try to fix it if it is too bad to bear".

"Carry the lightest equipment. Extra socks and spare shoes to keep feet dry".

"Wear running shoes that are designed for running, socks for running as well as a running vest”.

The strategy that changes the perception of the stressor is important in situations where the stressor cannot be changed or altered. This coping style can entail paying selective attention to relevant stimuli and thereby concentrating on the less stressful aspects of the situation, positive comparisons that reduce the perceived severity of the stressful situation and to reduce the perceived importance of the stressful situation or the outcome of the situation in relation to one's overall life situation. Examples of this strategy are illustrated in the following responses in extreme cold situations:

"Focus on my task and not my body".

"Do something so that you don't think of the cold".

"I motivate myself saying it is my imagination - it's not real".

In terms of sleep deprivation the following responses are typical of the well prepared ultra distance athlete:

"Nothing physical - but mentally you have to force yourself not to sleep. Nothing will happen to your body physically but it is a mental obstacle".

"Try not to think of sleep too much".

"Be prepared for less sleep and keep on thinking of finishing the event".

It is also clear that the strategy to focus on the symptoms of stress is the strategy that was used the least by the participants. The coping style does not focus on the situation itself, either directly or by changing the meaning or perception. The focus is rather on the resultant stress itself and entails basic stress management techniques. In terms of altitude the following responses are typical:

"I relax and try to control my breathing".

"You must just stay calm so that you do not make mistakes before any action".

When the wind becomes unbearable the athletes manage the stress in the following way:

"I just relax and let the wind cool me down".

"I breathe in and out (deeply) and try to deal with the frustration".

The endurance athletes in this study seem to prefer to place themselves in stressful situations. They seem to have a perception that they are able to understand and control the outcome of most situations - specifically in endurance sport. Their own self-perception is that they can 
cope with the majority of stressors. This is supported by the theories of sense of coherence, self-efficacy and locus of control where the perception and ability to make meaning out of any given situation, as well as the ability to understand and manage the situation is central to the individual's self-perception that is needed to cope with adversity. These findings are supported by research regarding anxiety and sport performance, the relationship of coping and its perceived effectiveness regarding positive and negative affect in sport (Ntoumanis \& Biddle, 1998).

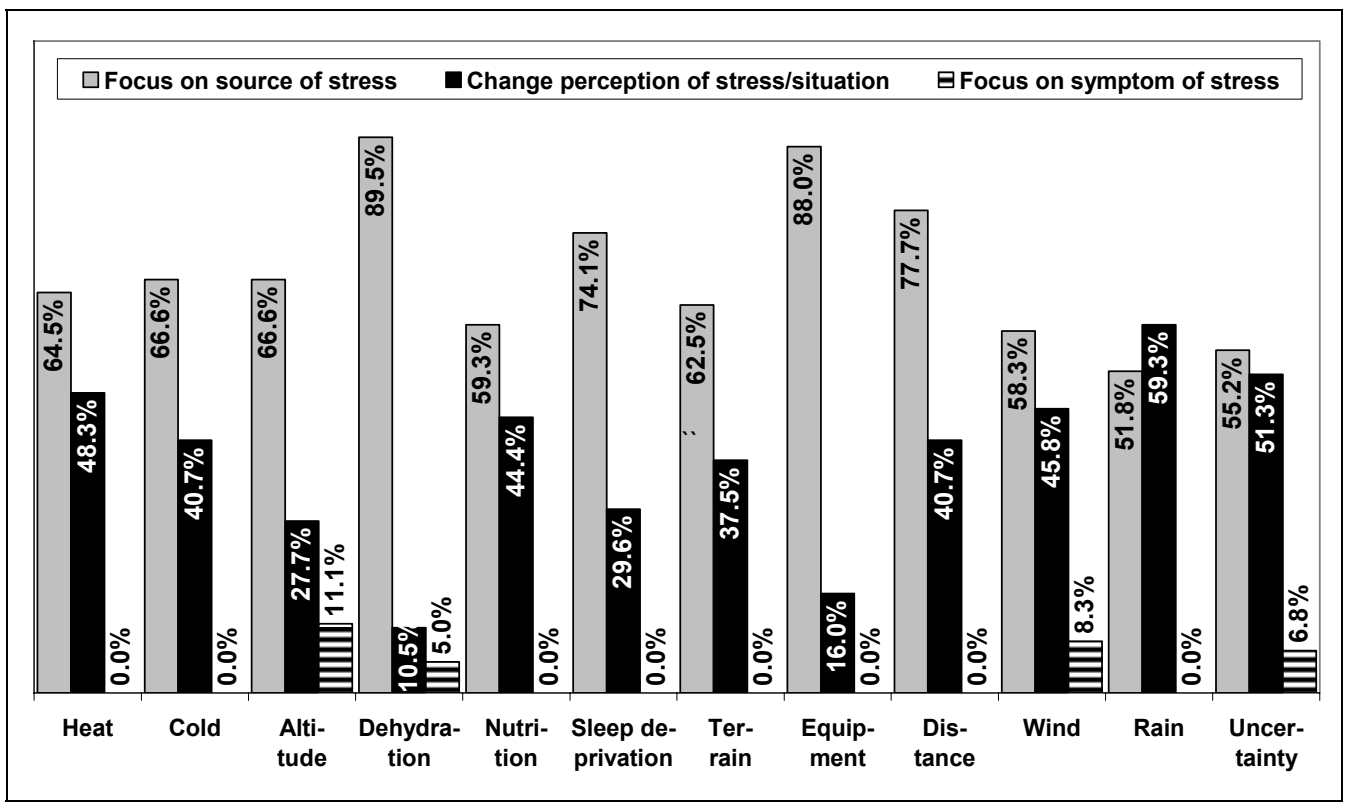

\section{FIGURE 1. COPING STRATEGY DISTRIBUTION PER ENVIRONMENTAL STRESSOR}

This perception of the self is only valid as long as it is tested on a regular basis. In other words, to reinforce their positive self-perception, endurance athletes continuously need to prove to themselves (and sometimes other people) that they can cope in difficult and possibly even life-threatening situations by participating in endurance events. This finding is supported by studies of Wurtele (1986), and Lane et al. (2002) that indicate that self-efficacy is the strongest predictor of performance for novice athletes, while previous performance is the best predictor for experienced athletes. Therefore, continued successful experiences in endurance events will increase self-efficacy to cope with difficulties and challenges.

The greater majority of endurance athletes who participated in this study perceive problems and difficulties in a positive manner. They see them as challenges that can be overcome, as learning opportunities and as opportunities for personal growth. Studies by Skirka (2000), Lane et al. (2002), Bandura and Locke (2003), and Sheldon (2005) found that many successful athletes perceive problems as positive challenges and as opportunities for personal growth as well as opportunities to improve their mastery of their sport discipline. Although the majority of these studies were done on non-endurance athletes, their findings support the results of this study. 
All the athletes in this study believed that they had the ability to overcome at least some of the challenges of endurance sport. The responses could be divided into three groupings: those who believed that they had the ability to overcome all challenges $(28 \%)$, those who believed that they would be able to overcome most challenges $(38 \%)$, and those who believed that they would be able to overcome some of the challenges (34\%). These findings are supported by theory and research conducted on recycling misconceptions of perceived self-efficacy (Bandura, 1984), the effects of personal and competitive self-efficacy and differential outcome feedback on subsequent self-efficacy and performance, self-efficacy and health behaviours (Conner \& Norman, 1995), negative self-efficacy and goal effects (Bandura \& Locke, 2003), the role of coping style, social support and self-concept in resilience of sport performance and physical and psychological predictors of perceived ability in adult male and female tennis players (Sheldon, 2005).

These studies indicate that a positive perception of own abilities (self-efficacy) is characteristic of successful athletes. It predicted successful performance during sporting events and were also shown to be an indicator of general wellbeing. Furthermore, they believe that they have sufficient resources available to overcome these challenges and that the pursuit of these challenging situations is meaningful. An interesting trend is that even those athletes who are unsure of their ability to overcome all challenges attribute this to a lack of effort, training or control over the situation - not necessarily lack of ability. By training harder, preparing and planning better and by learning from previous mistakes, they feel that they will be able to overcome the challenges of endurance sport.

\section{CONCLUSION}

This study determined that non-elite athletes mainly use strategies where they attempt to change the source of stress to cope with environmental stressors during endurance events. This is followed by strategies that attempt to change the individual's perception of the stressor or stressful situation. Only a small number of athletes used strategies that focused on the symptoms of stress. Most of the endurance athletes perceived problems and challenges as constructive. The majority of endurance athletes had a positive perception of their own abilities and regularly placed themselves in situations of danger or extreme stress to test this ability. Successful performance in these situations leads to an increase in performance and consequently an increase in perception of own abilities.

\section{REFERENCES}

ALDWIN, C.M. (1993). Coping with traumatic stress. The National Centre for PTSD, 4(3). Hyperlink [http://www.ncptsd.org/publications/rq/rqpdf/V4N3.PDF]. Retrieved 22 September 2004.

ANSHEL, M.H. (1990). Toward validation of a model for coping with acute stress in sport. International Journal of Sport Psychology, 21: 58-83.

ANSHEL, M.H. \& KAISSIDIS, A.N. (1997). Coping style and situational appraisals as predictors of coping strategies following stressful events in sport as a function of gender and skill level. British Journal of Psychology, 88: 263-276.

ANTHONY, P.N. (1996). Motivational attributions that justify an ultra-triathlete's need to perform. Unpublished Masters thesis. Pretoria: University of Pretoria. 
ANTONOVSKY, A. (1991). The salutogenic approach to family system health: Promise and danger. European congress on mental health in families, Prague, Czechoslovakia. Hyperlink [http://www.a-golem. html]. Retrieved 20 March 2005.

ARMSTRONG, L.E. (2000). Performing in extreme environments. Champaign, IL: Human Kinetics.

BABBI, E. (1995). The practice of social research ( $7^{\text {th }}$ ed.). Belmont, NY: Wadsworth.

BANDURA, A. (1984). Recycling misconceptions of perceived self-efficacy. Cognitive Therapy and Research, 8(3): 231-255.

BANDURA, A. \& LOCKE, E.A. (2003). Negative self-efficacy and goal effects revisited. Journal of Applied Psychology, 88(1): 87-99.

BLOOMFIELD, J.; FRICKER, P.A. \& FITCH, K.D. (1992). Textbook of Science and Medicine in Sport. Melbourne: Blackwell Scientific Publications.

BROOK, N. (1987). Endurance running. Ramsbury, Malborough: The Crowood Press.

CAMPEN, C. \& ROBERTS, D.C. (2001). Coping strategies of runners: Perceived effectiveness and match to precompetitive anxiety. Journal of Sport Behavior, 24: 41-63.

CONNER, M. \& NORMAN, P. (1995). Predicting health behaviour: Research and practice with social cognition models. Buckingham: Open University Press.

COX, R.H. (2002). Sport psychology. Concepts and applications $\left(5^{\text {th }}\right.$ ed.). New York, NY: McGrawHill.

DALE, G. (2000). Distractions and coping strategies of elite decathletes during their most memorable performances. The Sport Psychologist, 14: 17-41.

DETTWEILER, A.E. (1991). Physical and physiological characteristics of participants in the 1987/1988 Ultra man competition. Unpublished Masters thesis. Pretoria: University of Pretoria.

ELIOT, J.F. (2005). Motivation: The need to achieve. In S. Murphy (Ed.), The sport psych handbook (318). Champaign, IL: Human Kinetics.

GOULD, D.; EKLUND, R. \& JACKSON, S. (1993a). Coping strategies used by more versus less successful Olympic wrestlers. Research Quarterly for Exercise and Sport, 64: 83-93.

GOULD, D.; FINCH, L.M. \& JACKSON, S. (1993b). Coping strategies used by national champion figure skaters. Research Quarterly for Exercise and Sport, 64(4): 453-468.

HESSE-BIBER, S.N. \& LEAVY, P. (2004). Approaches to qualitative research. A reader on theory and practice. Oxford: Oxford University Press.

JARVER, J. (1989). Long distances. Contemporary theory, technique and training. Mountain View, CA: Tafnews Press.

KELLMANN, M. (2002). Enhancing recovery. Preventing underperformance in athletes. Champaign, IL. Human Kinetics.

LANE, A.M.; JONES, L. \& STEVENS, M.J. (2002). Coping with failure: The effects of self-esteem and coping on changes in self-efficacy. Journal of Sport Behavior, 25: 23-41.

LAZARUS, R. (2000). How emotions influence performance in competitive sports. The Sport Psychologist, 4: 229-252.

LEVIN, P. (2003). Common responses to trauma and coping strategies. Patti Levin, LICSW, PsyD. Hyperlink [http://.www.trauma-pages.com]. Retrieved 14 September 2004.

MANN, D. \& SCHAAD, K. (2001). The complete guide to adventure racing. The insider's guide to the greatest sport on earth. New York, NY: Hatherleigh Press.

MARSCHAN-PIEKKARI, R. \& WELCH, C. (2004). Handbook of qualitative research methods for international business. Cheltenham: Edward Elgar.

MARSHALL, C. \& ROSSMAN, G.B. (1995). Designing qualitative research (2 ${ }^{\text {nd }}$ ed.). London: SAGE. 
NTOUMANIS, N. \& BIDDLE, S.J.H. (1998). The relationship of coping and its perceived effectiveness to positive and negative affect in sport. Personality and Individual Differences, 24(6): 773-788.

O’NEIL, J.W. (2002). Realities of war: Fear, anxiety and stress in combat. 7 Medical Battalion Group, Lyttelton. Unpublished military training manual. Pretoria: 7 Medical Battalion Group.

REBER, A.S. (1995). The Penguin dictionary of psychology (new edition). London: Penguin Books.

SEILER, S. (1996). Efficiency and endurance performance. Stephan Seiler. Hyperlink [http://home.hia.no/ stephens/exphys.htm]. Retrieved 7 July 2003.

SELYE, H. (1974). Stress of life. New York, NY: McGraw-Hill.

SHELDON, J.P. (2005). Physical and psychological predictors of perceived ability in adult male and female tennis players. Journal of Applied Sport Psychology, 17: 48-63.

SKIRKA, N. (2000). The relationship of hardiness, sense of coherence, sports participation, and gender to perceived stress and psychological symptoms among college students. Journal of Sports Medicine and Physical Fitness, 40(1): 63-70.

STEVENSON, C.D. \& BIDDLE, S.J. (1998). Cognitive orientations in marathon running and "hitting the wall”. British Journal of Sports Medicine, 32: 229-234.

TAYLOR, S. (1998). Coping strategies. Psychosocial Working Group. Hyperlink [http://www.traumapages.com]. Retrieved 14 September 2004.

VAN BREDA, A.D. (2001). Resilience Theory: A literature review with special chapters on deployment resilience in military families \& resilience theory in social work. Unpublished research report. Pretoria: Military Psychological Institute.

WANN, D.L. (1997). Sport psychology. Upper Saddle River, NJ: Prentice-Hall.

WEINBERG, R.S. \& GOULD, D. (2003). Foundations of sport and exercise psychology (3 ${ }^{\text {rd }}$ ed.). Champaign, IL: Human Kinetics.

WURTELE, S.K. (1986). Self-efficacy and athletic performance: a review. Journal of Social and Clinical Psychology, 4(3): 290-301.

Prof. Barend J.M. Steyn: Department of Biokinetics, Sport and Leisure Sciences, University of Pretoria, Pretoria 0002, Republic of South Africa. Tel.: +27 (0)12 420 6094, Fax.: +27 (0)12 420 6099, E-mail: ben.steyn@up.ac.za 